\title{
THE OBJECTIVE OF THE NEW ZEALAND SEISMIC DESIGN CODE
}

\author{
o. A. Glogau*
}

\subsection{SYNOPSIS}

The writer discusses some aspects of the proposed revision of the New Zealand Seismic Design Code.

The degree of sophistication of a code must be related to the accuracy of factual information available and the validity of assumptions that have to be made.

The selected level of specified lateral code loading is related to a number of considerations some of which are not obvious on superficial examination of a proposal.

Known earthquake performance whenever available must be the most important reference point for code writers.

\subsection{INTRODUCTION}

The proposed revision of N.Z.S. Chapter 8 now to be called "General structural Design and Design Loadings" comes at a time when code writers in most seismic areas are reviewing their current provisions in the light of recent earthquake damage, particularly that due to the 1971 San Fernando and 1968 Tokachi-oki earthquakes.

The code must maintain a reasonable degree of balance between the requirements of the bulk of busy designers who need a safe "Cook book" and tho se who wish to apply more sophisticated methods without being unduly hampered by the code. There must be adequate restraints to protect the interests of the public against inexperienced designers willing to accept the print out of their computers as gospel regardless of the validity of their as sumptions.

It is a temptation to write codes in which the seismic loading is derived from the combination of up to twelve different factors, including such concepts as balanced death risk. Such an approach gives a code a scientific look - or should it be called pseudo-scientific because experts disagree on many of the vital factors by several hundred percent. In the final analysis, therefore, the problem resolves itself to deciding whether there is sufficient evidence of inadequate current code performance to require change.

* Chief structural Engineer, Ministry of Works, Wellington. Chairman S.A.N.Z. Loading Committee. This paper is essentially as presented at the Symposium "structural Design for Buildings" held at Auckland University in August 1972 .

\subsection{PURPOSE}

The By-Law portion of the code sets out the following aims. It states that the design and construction of any building shall be such that:

(a) Al1 loads 1ike 1y to be sustained during the life of the building will be sustained with an adequate margin of safety;

(b) Deformations of the building will not exceed acceptable levels;

(c) In the events that occur occasionally, such as moderate earthquakes and severe winds, structural damage will be avoided and other damage will be minimised;

(d) In the events that occur very seldom, such as major earthquakes and extreme winds, collapse and irrepairable damage will be avoided and the probability of injury to or loss of life to people in and around the building will be minimised.

It should be noted here that the code does not guarantee that its aims will be achieved in all cases. It must be admitted that we never know our world perfectly and set out to achieve an acceptable probability of safety during the structure's lifetime.

How can the code achieve its objectives? Apart from the requirements for ductile detailing of a structure, which must be specified in the materials codes, the selection of appropriate seismic loads is of greatest significance.

\section{0 DETERMINATION OF DESIGN EARTHQUAKE EFFECTS}

The design earthquake effects are usually determined by one of the following methods:

\section{(a) Static}

In this method a constant percentage of the dead and probable liveload at each level is applied horizontally to the structure. The method should be limited to one and perhaps two-storey structures.

\section{(b) Pseudo-Dynamic (Equivalent Static)}

This method requires an approximate determination of the fundamental period of the structure. A percentage of the total dead and probable liveload is then distributed over the height of the building in a manner that simulates dynamic effects. For buildings of uniform vertical mass distribution the result is the familiar triangular load distribution. Additional modifications are made for slender 
114 structures to improve simulation of the "Whip" effect. This method gives good results for regular and medium height buildings.

(c) Dynamic

(i) Spectral Modal Analysis: In this method the "structural design spectrum" together with the response of each mode of the structure las determined from the relationship of a set of equivalent single mass oscilators representing the more complex vibration system) is used.

(ii) Time Dependent Elastic Response Method: In this method a mathematical model of the structure is subjected to the time history record of an actual or synthetic earthquake, the selection of which is subject to certain minimum spectral values specified in the code.

A more realistic variant of the above is a nonmelastic method. This method recognises the formation of plastic hinges in the structure at certain times during the response.

All methods, including the dynamic methods, suffer at present from serious short-comings because of a number of assumptions that have to be made with regard to the structural behaviour and the nature of the earthquake motion. Nevertheless, the last mentioned method offers the best hope for the future of gaining insight into the aseismic behaviour of modern structures.

\subsection{FACTORS INFLUENCING EARTHQUAKE EFFECT ON STRUCTURES}

Earlier in this paper the writer has advised against over-sophistication in determining the earthquake forces. Nevertheless while many significant factors cannot yet be determined with a sufficient degree of accuracy for practical purposes designers should be aware that the simple familiar formula

$$
V=C_{d} W_{t}
$$

is in fact very complex. By appreciating how it is made up, and what significance the various uncertainties involved have, the designer is in a better position to make a more rational decision in particular cases. Although it is not too difficult to write down twice as many factors it is convenient for purposes of this discussion to distinguish only the following:

$$
C_{\mathrm{d}}=\mathrm{Z} \cdot \mathrm{A} \cdot \mathrm{H} \cdot \mathrm{P} \cdot \mathrm{I} \cdot \mathrm{R} \text {. }
$$

Complete separation of effects is not practical but largely the various factors are meant to represent the effects 1 isted below:

\section{$2=$ Seismissity}

including.

Maximum base rock acceleration considered likely during the life of the structure.

Probable epi-central distances of strong and moderate motions.

The frequency of severe and moderate earthquakes which is also an important consideration but can better be allowed for in the "P" factor given below.

$A=$ dynamic amplification factor depending on earthquake motion and structural period.

To account for flexible soil effects the rock motion spectrum is modified either mathematically or by using actual records obtained on the surface of the soil. A number of other factors cannot be treated in isolation such as:

structure-soil interaction, foundation type (piles, deep basements, etc.), feedback.

\section{$\mathrm{H}=$ Structural damping reduction}

A variety of values can be found in the 1iterature. Some authors use different values, for various regions of the response spectrum(1) The following may apply:

$$
\begin{aligned}
& \mathrm{H}_{2}: \mathrm{H}_{5}: \mathrm{H}_{7}: \mathrm{H}_{10}=0.7: 0.48: 0.38: 0.33= \\
& 2.1: 1.5: 1.15: 1
\end{aligned}
$$

Regardless of whether or not a code introduces a separate factor for damping this effect may account for significant differences in ductility demand.

$$
\underline{P}=\text { Seismic performance reduction }
$$

$P=\frac{s \gamma}{r}$ where $r=4$ in NZS 1900 Chapter 8

\section{Structural type factor $S$}

Moment resisting space frames (M.R.S.F.) designed for ductility and with adequate number of beam redundancies in each storey

M.R.S.F. and "shear towers" designed for ductility

Face loaded walls and partitions

Shear wall structures incorporating an independent ductile moment resisting space frame

Shear walls (seismic energy presumed to be essentially dissipated in a shear mode)

Buildings with diagonal bracing capable of plastic deformation in tension only

All other structures and buildings including chimneys, tanks or reservoirs and full contents

\section{Comment}

The reduced $S$ factor for shear wall struct. ures incorporating a ductile M.R.S.F. is perhaps more in recognition of reduced risk due to an independent propping system for the floor than in expectancy of superior structural performance for the combined system. Adequate number of beam redundancy must be defined. Structures having a low number of beam redundancies in a particular storey are very vulnerable if deterioration of a plastic beam hinge should occur, e.g. violent torsional motions could follow. Column hinge mechanism are of course outside the scope of the proposed code.

\section{Structural material factor}

Structural steel 
Structural material factor Cont.

Structural timber (shear wall structures) 0.8

Reinforced concrete

Reinforced masonry

NOTE

Owing to lack of quantitative information the above are based on observer performance, limited tests, intuition, practical considerations and overseas practices etc.

What matters is the value of 5.8

Typical Examples

\section{$\underline{5 \times 8}$}

Ductile M.R.S. Frame in

steel, adequate redundancy

$$
0.8 \times 0.8=0.64
$$

Ductile M.R.S. Frame in rein-

forced concrete $1 \times 0.8=0.8$

Reinforced concrete shear wall

bui.1ding

$1.6 \times 1=1.6$

Reinforced masonry building

(a11 types)

$1.6 \times 1.2=1.92$

NOTE

Differences in damping are significant. The value of $\gamma=0.8$ for timber shear walls is in recognition of high damping. Similarly a welded structural steel frame with light cladding designed to the above value will need to have an increased ductility capacity of say $\frac{2.1 \times 1}{1.15 \times 0.8}=2.3$ over that of a reinforced concrete frame with heavy claddings. On the other hand a coupled shear tower may require only two-thirds the ductility of a reinforced concrete frame if both were designed for the same $P$ (and two-thirds $\times 0.8=0.53$ for $5.8=$ 1.0.)

Other considerations such as the inherently greater safety against overall instability of a well detailed shear tower compared with that of a ductile frame are included.

\section{$I=$ Importance}

Occupancy (in and around buildings, function, costs, structure 1 ife) - These are all related to the acceptable risk of failure.

\section{Type of occupancy}

Non-public buildings (as at present there may have to be a lower limit for I say 1.0 in seismic zone $C$ )

Public buildings

Essential facilities that should be completely functional following seismic disaster

\section{NOTE}

Essential facilities include hospitals and medical facilities having surgery and emergency treatment areas, radio and television facilities, fire and police stations, designated civilian emergency centres and civil defence centres. Essential facilities may become non-functional due to secondary damage of enclosing materials and damage to equipment and special attention must be given to these aspects in their designs.

\section{$\mathrm{R}=$ Risk factor}

The considerations here are those which are not included in normal building load factor considerations. $R$ should be taken as 1.0 except as below:

Buildings accommodating more than say 1000 peop1e

Distribution facilities for natural gas, coal gas and petroleum products in urban areas

Structures and installations containing or directly supporting toxic liquids, gases, etc.

Another example in this category are cantilevered storeys (and parts) for which the present code specifies in fact $\mathrm{R}=1.5$ to 3.0. Redundancy considerations are here included.

\subsection{SMALL BUILDINGS}

To meet practical reality higher $\mathrm{C}_{\mathrm{d}}$ factors for smaller structures designed and detailed to a lower standard are needed. These structures could be designed without consideration of vertical and concurrent earthquake effects. Member proportions could depart from those prescribed for "ductile" frames. Column hinges would be permitted etc. Most of these structures, say of two to three storeys and limited area could be designed for 1.5 to 2 times the normal $C_{d}$ values without great difficulty or expense.

\subsection{PRACTICAL CODE FORMULA FOR $\mathrm{C}_{\mathrm{d}}$}

To simplify the design process for the bulk of structures considered it is convenient to combine as many factors as possible and to prescribe variations only for departures from the norm. Thus we arrive at the familiar C curves of the present Chapter 8 . For the proposed revision the writer believes that a slightly more sophisticated approach may be justified. The co-efficient $C$ may include the effect of $Z, A, H$ and a reduction factor for ductility. To obtain $\mathrm{C}_{\mathrm{d}}$ additional modifications for $I, S, \&$ and $R$ must be made. Thus we arrive at the two formulae:

$$
\begin{aligned}
& \mathrm{v}=\mathrm{C}_{\mathrm{d}} \mathrm{W}_{\mathrm{t}} \\
& \mathrm{C}_{\mathrm{d}}=\mathrm{C} \mathrm{I} \mathrm{s} \mathrm{R}
\end{aligned}
$$

This formula is best suited for design by method 3(b). The curves for C (fig. 1) modified into $C_{d}$ curves may be regarded as design spectra for particular cases and used in a Spectral modal analysis.

\section{DESIGN SPECTRA}

These may be specified in a number of ways. As discussed above the various factors Z.A.H. P.I.R. can be combined to give a set of simple graphs of $C_{d}$ coefficients as has been done in our present Chapter 8 . The peak values for the design acceleration spectrum may be arrived at as follows :

For a reinforced concrete frame structure with $\mathrm{T}=0.5$ seconds and a ground motion acceleration spectrum value $1.25 \mathrm{E} 1$ Centro N.S. $=0.4 \mathrm{~g}, \mathrm{~A}=6.4(1), \mathrm{H}=0.3$ (for $7 \%$ damping), 
116

$R=1, P=\frac{1}{4}$ (present code value).

$$
c_{d}=0.4 \cdot 6.40 .3 \cdot 1 \cdot 0.25 \cdot=0.192 \mathrm{I}
$$

This value corresponds to the maximum ultimate design earthquake coefficient for public buildings $(0.2 \mathrm{~g})$. In many buildings the material under capacity factor will be available as over strength so that "I" greater 1 is availabie.

It is important to note here that all factors are subject to uncertainties particularly the amplification factor "A" when soil effects are considered. However, there is insufficient evidence from earthquake damage to regard the end result, $0.2 \mathrm{~g}$ as grossly inappropriate for a ductile structure.

Provided the local ground motion spectrum and structural behaviour can be predicted with confidence the presentation (Fig. 2) currently gaining favour in California has advantages where a dynamic analysis is to be carried out. It is a development of the Tripartite

logarithmic charts proposed in reference

and is based on the observation that many smoothed response spectra for firm grounds exhibit characteristics where for certain ranges of periods either displacement, velocity or acceleration are constant. The response spectrum can thus be simulated by three straight lines called "basic structure spectrum". The "ground motion spectrum" for the locality is a set of three similar lines representative of the maximum motions expected, i.e. $0.33 \mathrm{~g}$ acceleration, 16 inches velocity, 12 inches displacement. The amplification factors are the ratios between the values of the structure spectrum and ground motion spectrum, e.g. $6.4,4.0,2.5$, respective1y.

The design spectrum (for shear and moments) is then obtained from the structure spectrum by the use of appropriate reduction factors to account for damping and ductility. The three regions of the basic structure spectrum are not scaled down by the same factors, e.g. the region where velocity is constant may be reduced by $\mathrm{H} \times \frac{1}{\sqrt{2 \mu-1}}=\frac{0.38}{\sqrt{7}}=0.14317 \%$

damping, ductility 4), 64 inches $x 0.143=9.15$ inches. The reduction factor for the constant displacement region may be $H=0.48 / 4=$

$0.12, \& 30 \times 0.12=3.6$ inches.

Although Tripartite charts have little advantage for use with non dynamic methods, they may of course be used in exactly the same manner as the curves in the present chapter 8 to obtain a basic seismic coefficient, e.g. for a building with $T=1$ second one selects a design acceleration coefficient from the graph (or computes it from the relationship $S_{a}=s_{v} \times \frac{2 H}{T}=9.15 \times 6.28 / 1=57.5$ inches per second square, i.e. $57.5 / 386.1=0.15 \mathrm{~g} .1$

Inelastic behaviour reduces moments and shears but not displacements and velocities and if these are computed from the design spectrum loadings they must be multiplied by the ductility factor $\mu$.

For purposes of comparison the present New Zealand curve for Public Buildings is also shown. Intended to be an envelope for a variety of rigid and intermediate soils and to cater for $10 c a 1$ and distant earthquakes, the curve results in a more conservative design for buildings with long periods. It should be remembered that the low design values of the constant velocity approach for longer periods often cannot be used because inter storey deflections become excessive, and designers then must use higher loadings.

\subsection{MODIF ICATION FOR FLEXIBLE SOIL}

This is one of the most difficult tasks facing Code writers. The modification for specified soil types and depths proposed for the next New Zealand Code is shown in fig. 1. Designers may be forgiven if their reaction to the proposed zone-A soft soil modification is "why bother"? Nevertheless it appears that the modifications are as far as it is possible to go in code form in the light of what is known at present. Mathematical treatments of the problems have been proposed and in a limited number of cases correlated with instrumental measurements. The results are, however, sensitive to the use of correct soil moduli and damping ratios, etc., which are strain dependent, ife. the level of earthquake motion considered. (4) The validity of the proposed New Zeal and Code curves depends to some degree on the following assumptions :

\section{For Seismic Zone A}

Curves 1 and 2 in figure (3) represent the response of a strong near focus earthquake on rigid and flexible soil respectively. Many experts believe that strong motions will not amplify on soft soils to a greater level than 1. Curve 3 is assumed to represent a strong distant earthquake. The change in spectral density, reductions for distance and degree of amplification by soil are not well known at present.

\section{For Seismic Zone C}

Curve 4 is intended to represent a moderately strong near focus earthquake on rigid soil; 5 and 6 distant severe earthquakes on rigid and flexible soils respectively. It is considered unwise to lower the short period portion of the zone $C$ curve at present and it is equally difficult to substantiate raising the long period end for soft soils further than proposed.

The code curves are not intended to protect against magnifications such as those reported by Yamahara.(2) If confirmed by other researchers the phenomenon will have to be investigated as part of site investigations.

\subsection{DESIGN OF PARTS AND PORTIONS}

Some recent considerations in this respect have been discussed by the author in a recent paper. ( 5$)$

\subsection{LOADING AND LOAD FACTORS}

A number of new equations are proposed. Those related to this discussion are the following :

$\mathrm{U}=1.4 \mathrm{D}+1.7 \mathrm{~L}_{\mathrm{R}}$

$\mathrm{U}=1.05 \mathrm{D}+1.27 \mathrm{~L}_{\mathrm{R}}+\mathrm{E}$ 
$=3 / 4\left(1.4 \mathrm{D}+1.7 \mathrm{~L}_{\mathrm{R}}\right)+\mathrm{E}$

$U=0.90+E$

$E$ is the ultimate design earthquake effect.

The total seismic load $W_{t}$ may be computed either as at present, using deadload plus a part of the liveload, or for the bulk of occupancy types having medium liveloads, simply as 1.12D. The end result as proved by computations (refer to Appendix) for a range of buildings is practically identical and additional work in computing a seismic liveload as well as the reduced 1 iveload $L_{R}$ is not warranted.

A change of a technical nature reflecting the growing recognition of strength design methods has been the elimination of the load factor from $E$. It does not seem logical to select a design earthquake fairly arbitrarily and then increase it for every design combination by $25 \%$ as we do at present. Compensating adjustments are made for the alternative (working stress design) method where necessary.

The curves shown in figure (1) for rigid soils (considering also the new ISYR factors) are thus similar to those in current use but incorporating the 1 oad factor 1.25 eliminated from the load factor equations.

\subsection{VERTICAL EARTHQUAKE EFFECTS}

Vertical ground accelerations of up to two-thirds of the horizontal have been recorded in the 1971 San Fernando earthquake 10.2 to $0.3 \mathrm{~g})$. Axial loads significantly reduce the ductility of reinforced concrete members, affect buckling of slender columns and if tensile reduce shear strength of concrete and masonry wa11s. It is thus proposed that for more important structures an additional vertical load term + $1.5 \mathrm{CIW}_{\mathrm{V}} \&(\mathrm{C}$ max. value for zone from figure 1) be included in the load factor equations when applied to columns and shear wa11s. (Amplification of vertical motions is not introduced at present).

The current code already provides for additional seismic loadings on horizontal cantilevers, particularly net upwards loads that require designers to reinforce also the lower races of cantilvers. Earthquake damage possibly arising from a combination of vertical and rocking motions has shown this to be necessary. Ductile detailing would normally protect more redundant frame members against load reversal in the span, and practical experience (transport accidents) indicates that even prestressed floor systems would not be seriously damaged.

\subsection{CONCURRENT EARTHQUAKE EFFECTS}

It is intended that in more important structures concurrent earthquake effects should be considered. This does not merely mean the simultaneous applications of earthquake motions in two directions but the effect of the simult aneous hinging of all beam members framing into a joint and at all levels above that joint. The reasoning is somewhat as follows:

Buildings designed for the earthquake loadings of the N.Z. Code must exhibit a significant amount of ductility. Under those circumstances there is a high degree of probability that beam hinges will form simultaneously in all beams framing into a junction and in many above for a significant fraction of the time of severe at tack.

Arising from this situation are severe shear forces in the beam column joint and high axial loads.

Concurrent hinging of all beams provides of course a large number of energy dissipating locations which should reduce ductility demand. Future investigation may indicate some form of a reduction factor for axial loads in columns due to beam hinging in high buildings due to this effect. It must be remembered, however, that there is uncertainty about the magnitude of the reduction factor for ductility in general and that the New Zealand reduction factor of 4 is not likely to be shown as being over conservative.

Because the formation of a temporary column hinge due to the combined moments and axial tension under concurrent loadings is not considered to be serious, this case of loading should be exempted, provided the shear strength of the column is maintained and the building has more than one bay in each direction.

\subsection{DESIGN METHODS}

(U1timate) strength design methods are preferred for all materials where adequate information on strength methods is available. Where the alternate (working stress) design method is employed the following two combinations of loadings must be considered:

$D+L_{R}+E$
$0.9 D+E$

To compensate for the $25 \%$ greater value of $E$ in the new Code the allowable stress increase where the above combinations apply has been increased by the same amount, i.e. to $1.25 \mathrm{x}$ $1.1 / 3=1.67$. The nett result is a slight reduction in material quantity when gravity and seismic effects are additive. The reasons for the change (and this affects wind load combinations not discussed here as well) is of course that the working stress design method in its present form is dangerous with regard to stress reversal. The explanation of the lack of safety against failure due to reversal is simply that the usual factor of safety is applied to the difference between two independent load effects of similar magnitude. The use of load factors for combinations of gravity, wind and earthquake loads also in the working stress design method is the only way of increasing safety. Changes in allowable stress cannot achieve this result.

Figure (4) shows on a comparative basis the result of the proposed changes for the case of $L=0.5 \mathrm{D}$, the material under capacity factor has been taken as 0.9 and a $10 \%$ increase allowed for effective depth. The result is not sensitive to $L / D$ ratio changes.

\subsection{CONCLUSION}

The writer believes that there is no evidence that the average seismic loadings specified by the current New Zealand Code are 
118

not adequate for ductile structures. The bulk of N.Z. Structures are not adequately ductile in terms of the code loading and significant load increases are therefore required for structures not capable of stable flexural energy dissipation under repeated reversed loadings. Moderate code modifications, for flexible soil effects can be made now and further modifications may be required when more ground motion records due to strong, near and distant earthquakes become available. The Code should recognise the serious effect of vertical accelerations and concurrent two directional beam hinging mechanisms on column performance. A greater degree of damage control is required. Detailing for ductility is of greatest importance and provisions relating to this aspect in the material codes must be up-dated.

\subsection{ACKNOWLEDGEMENTS}

The writer, although not aware of any significant conflict of opinion, wishes to make it clear that the views expressed are his own and not necessarily those of the loadings committee as a whole, nevertheless the assistance of the members of this committee is gratefully acknowledged.

\section{REFERENCES}

1. Newmark and Hall, Seismic Design for Nuclear Reactor facilities. Fourth World Conference on Earthquake Engineering, Chile, 1969.

2. Yamahara. The inter-relation between frequency characteristics of ground and earthquake damage to structures, Japan society for Soil Mechanics, Vol. 10, No. 1 , 1970 .

3. Newmark and Rosenblueth, Fundamentals of E.Q. Engineering.

4. Taylor P.W., Surface Layer Modification of Earthquake Motion, Seminar, Auckland 1970 .

5. Glogau and Armstrong, The design of Public Buildings, Seminar, Auckland 1972.

\section{SYMBOLS NOT DEFINED IN TEXT}

$\mathrm{V}=$ Total lateral force or shear at base.

$W_{t}=$ Total seismic 1oad. $(D+$ part L. $)$

$W_{V}=1.05 \mathrm{D}+1.27 \mathrm{~L}_{\mathrm{R}}$

C = Basic seismic coefficient given in fig. 1. (Incorporates present load factors of 1.25 given in NZS/1900, Ch. 8).

$\mathrm{C}_{\mathrm{d}}=$ Horizontal seismic design coefficient.

D = Dead load and related effects.

$L=$ Live load and related effects.

$L_{R}=$ Reduced $L$, a function of contributing area.

$E$ = Earthquake effect (ultimate design).

$\mathrm{U}=$ Required ultimate load capacity.

\section{APPENDIX}

In figures $1 \mathrm{~A}$ to $2 \mathrm{C}$ a comparison is made of the results of present New Zealand practice and the proposed equations when applied to a typical three storey and fourteen storey reinforced concrete building. Also shown in Fig. (IC and $2 B$ ) are the results of omitting live load altogether from $E$ as is done in U.S. practice. It can be seen that by raising $W_{t}$ based on $D$ by about $12 \%$ (or the present coefficient of E from 1.25 to 1.4) beam end moments are restored to present levels. The alternative (retaining seismic live load for computing $w_{t}$ ) gives similar results but the effort of computing both reduced live 1 oad and seismic load appears excessive and not warranted for most buildings carrying live loads from 30 to $100 \mathrm{lbs} / \mathrm{sq}$. ft.

Figures ( $1 D$ and $2 C$ ) show how small the effect is on results of the equations of varying seismic coefficiencies. While the proposed equations are thus seen to give reasonable results for ordinary buildings they are not intended to apply to structures with unusual weight distributions. Slightly different results would be obtained for very 1 ight or very heavy buildings, but an adjusting factor for $W_{t}$ related to $L / D$ does not seem warranted.

It is worth remembering in this connection that in ductile frame design the beam end moments are one of the most significant parameters in the design of all framing members. 


$$
V=C_{d} W_{t} . \quad C_{d}=C I S \gamma R
$$

- Rigid and intermediate subsoils.

- - Flexible subsoils.

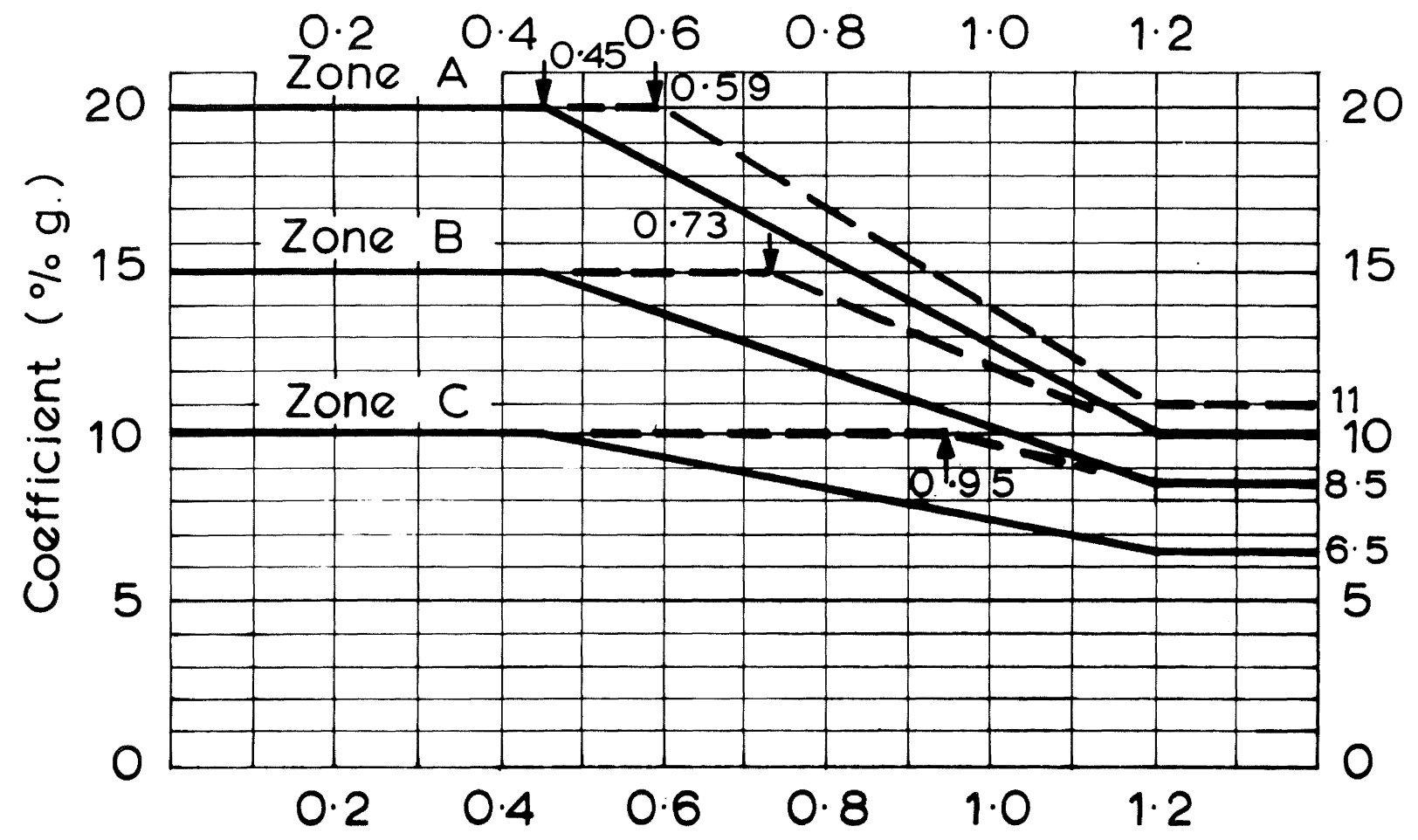

Period in Seconds

Fig. 1 BASIC SEISMIC COEFFICIENT ' $C$ ' for Seismic Zones $A, B \& C$. Also refer Clause: 


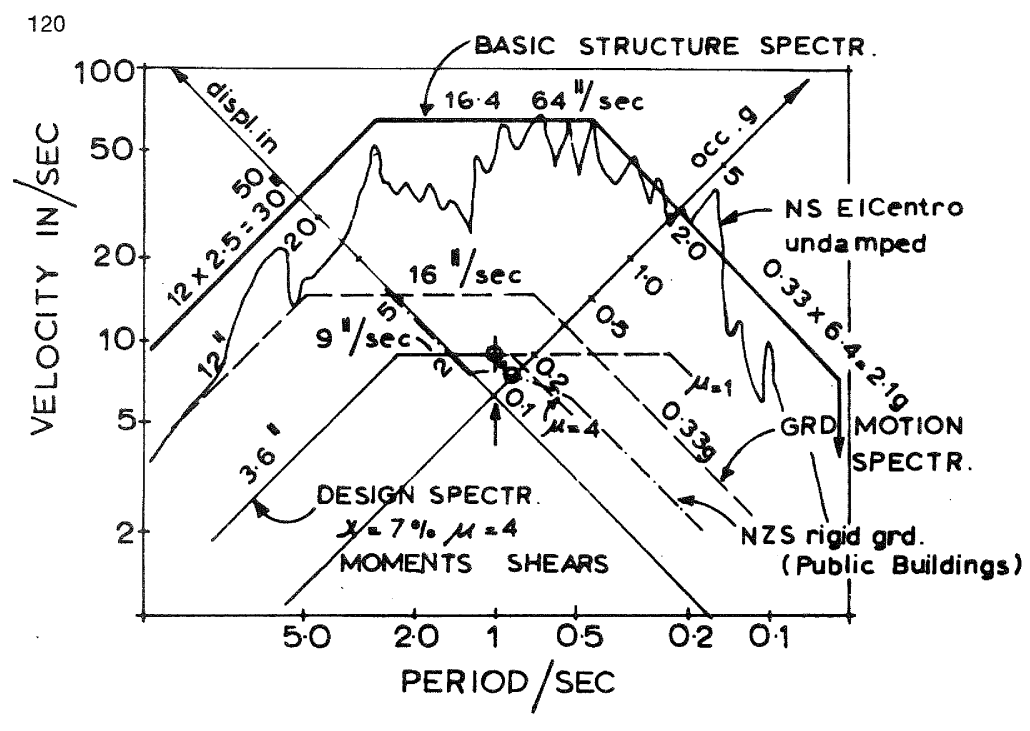

FIG 2

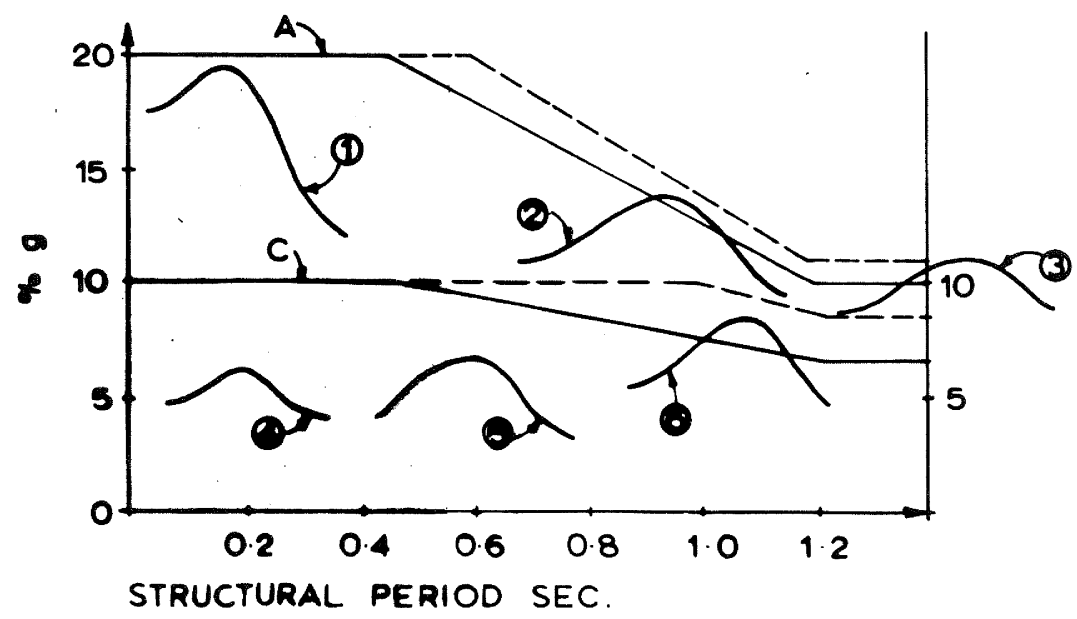

FIG. 3

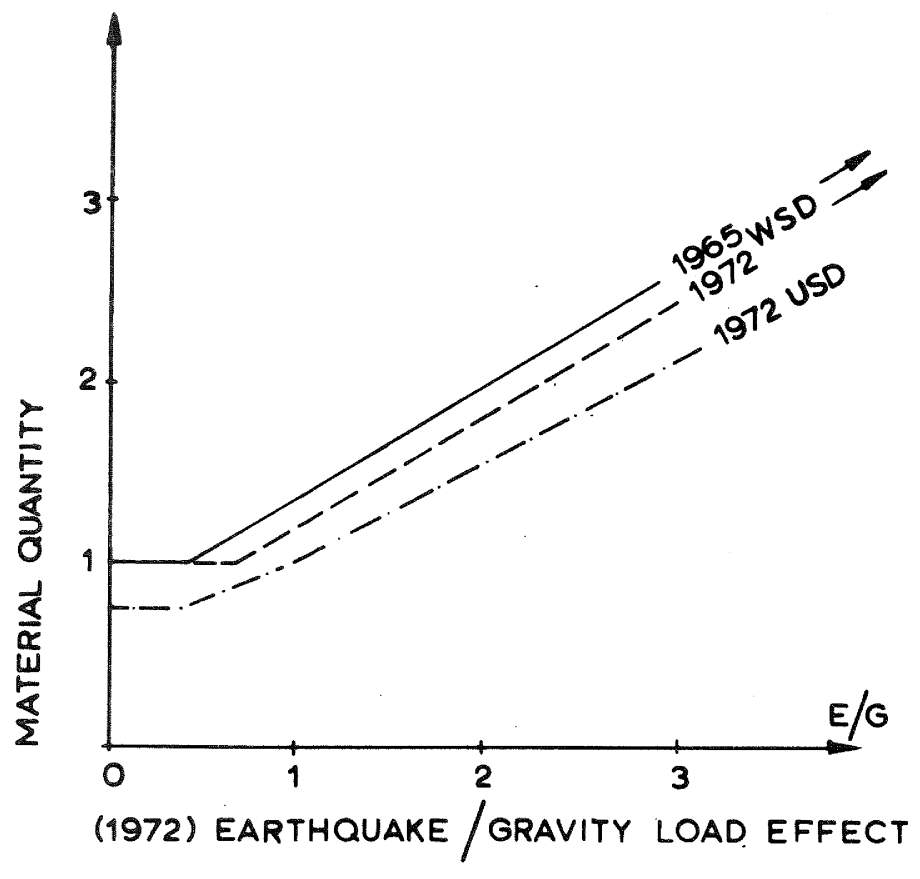

FIG. 4 


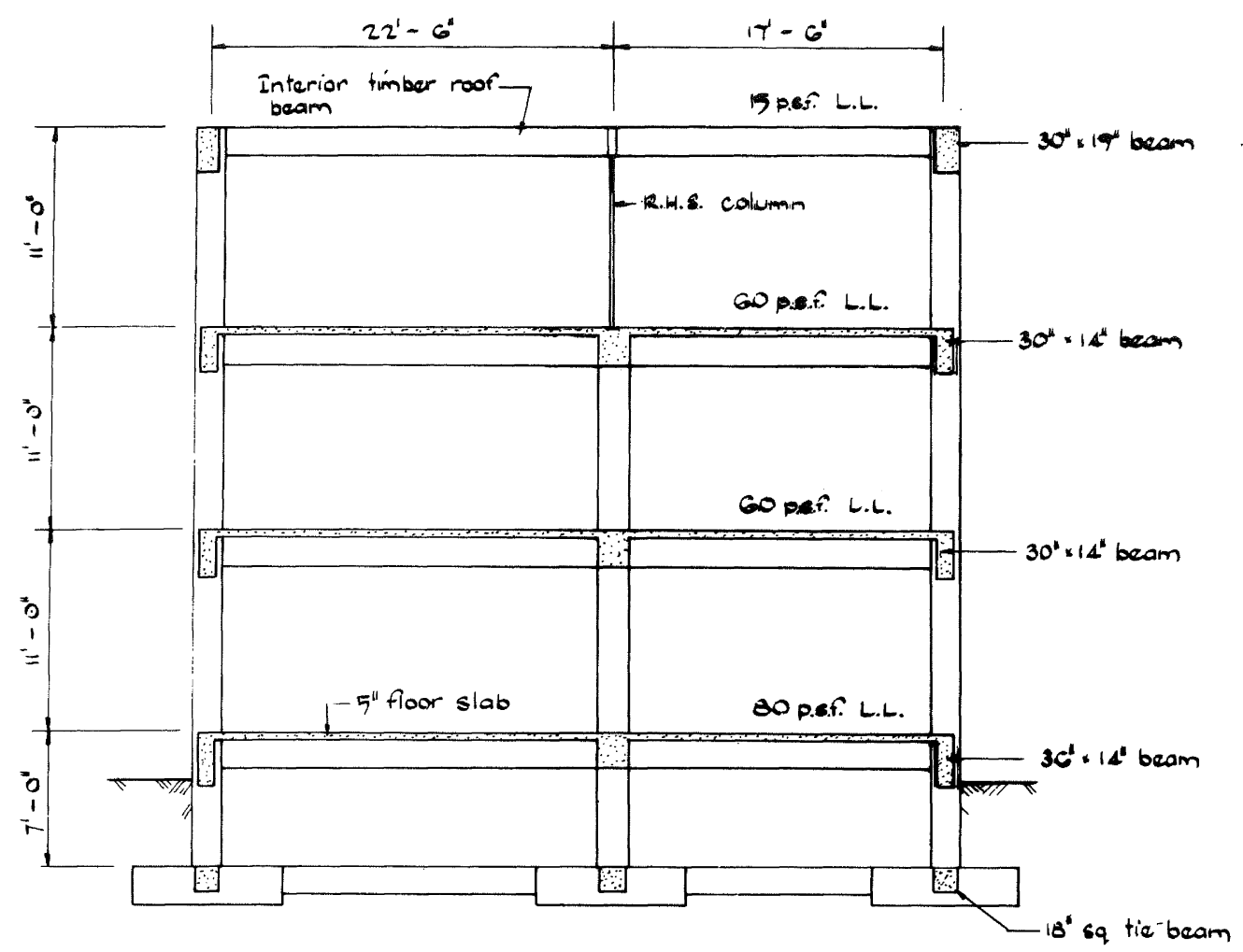

SECTION $A-A$

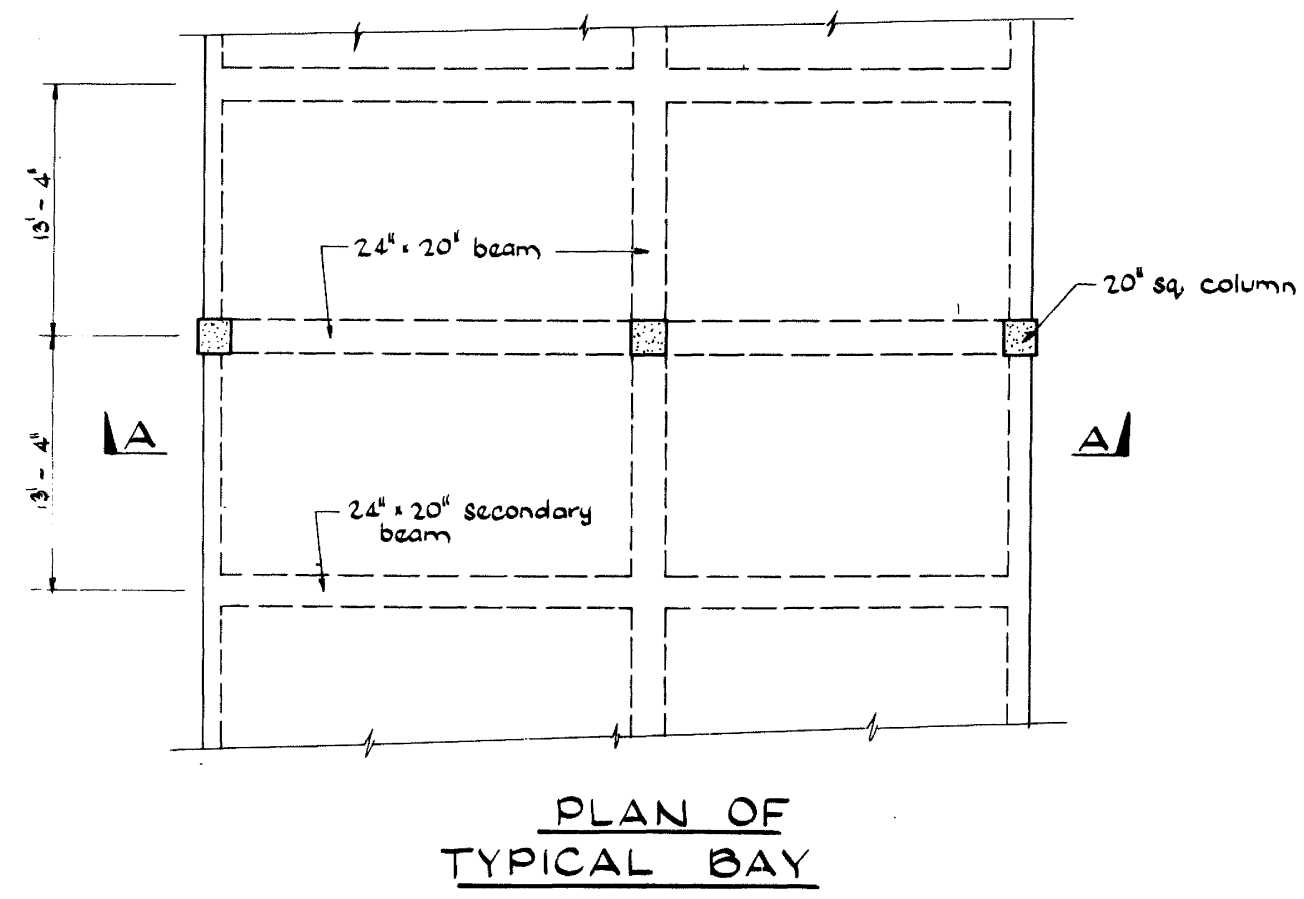



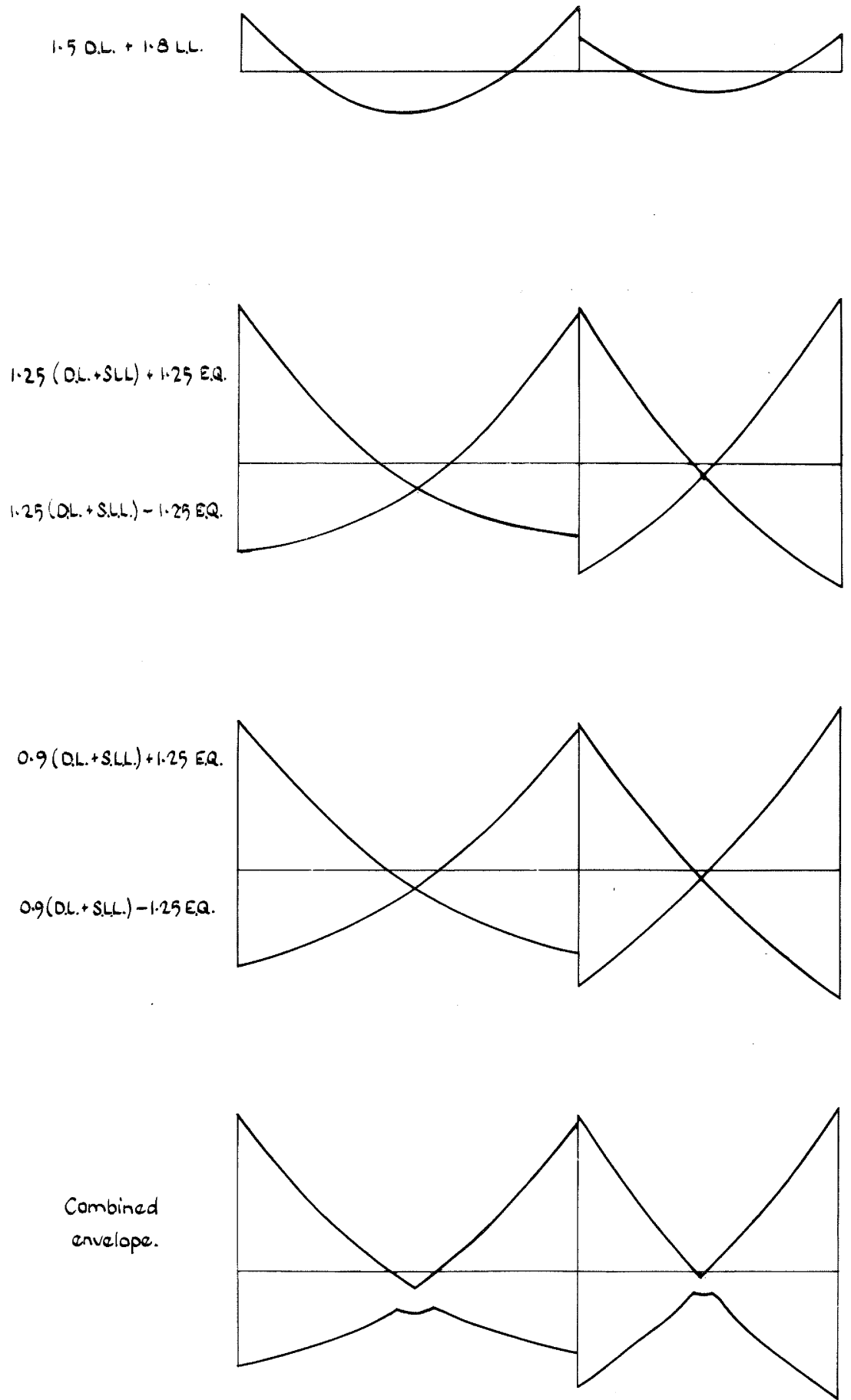

B.M. DIAGRAMS FOR IST FLOOR BEAMS. 


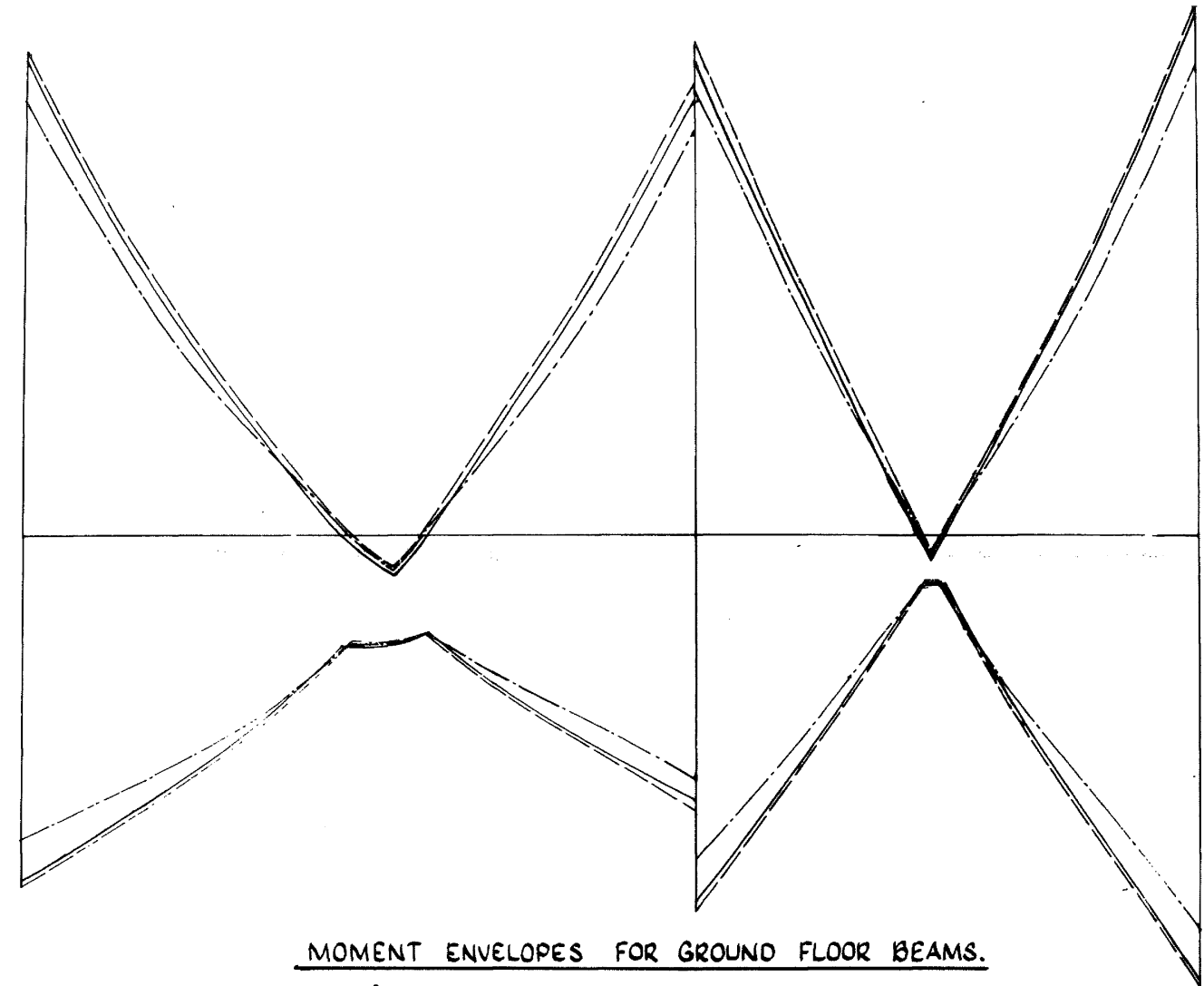

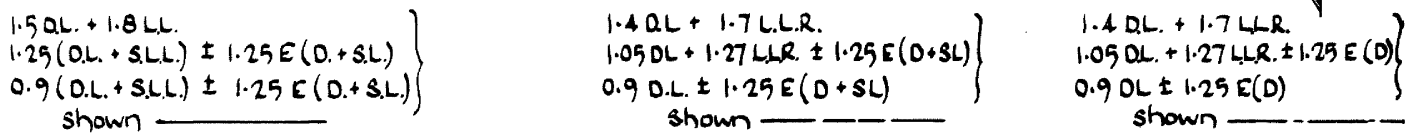
shown - shown - -

Vert. scale: I' to 1000 Kip in.

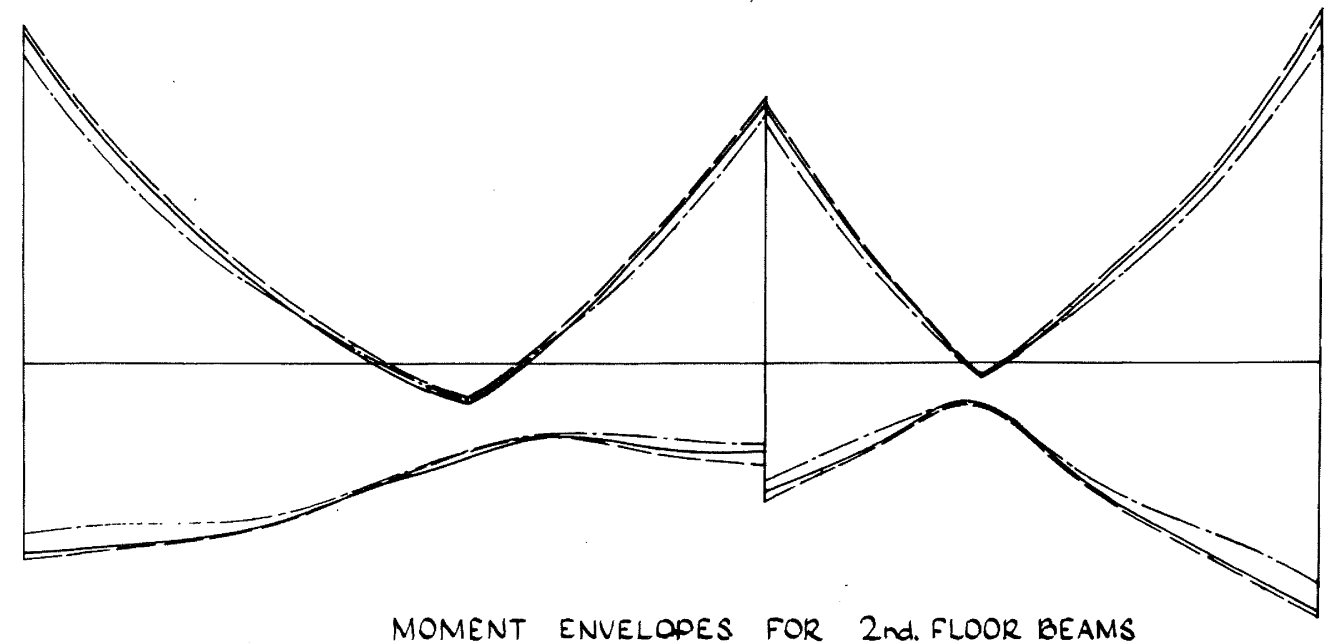

MOMENT ENVELOPES FOR 2nd. FLOOR BEAMS

1.5O.L. +1.8LL

$1.25(0 . L+S L L) \pm 1.25 E(D+S L)$

$0.9(0 L+S . L L) \pm 1.25 E(D+S L)$ shown
$1.4 \mathrm{OL}+1.7 \mathrm{LLCR}$

$\quad 1.050 L+1.27 L L R \pm 1.25 E(D)$ 0.9 OL. $\pm 1.25 E(D+S L)$ shown

Vert. scale it to 1000 Kip in.
1.05 DL. $+1.27 L L R \pm 1.25 E(D)$
$0.90 . L . \pm 1.27 L L R \pm 1.25 E(0)$ shown - - . - 


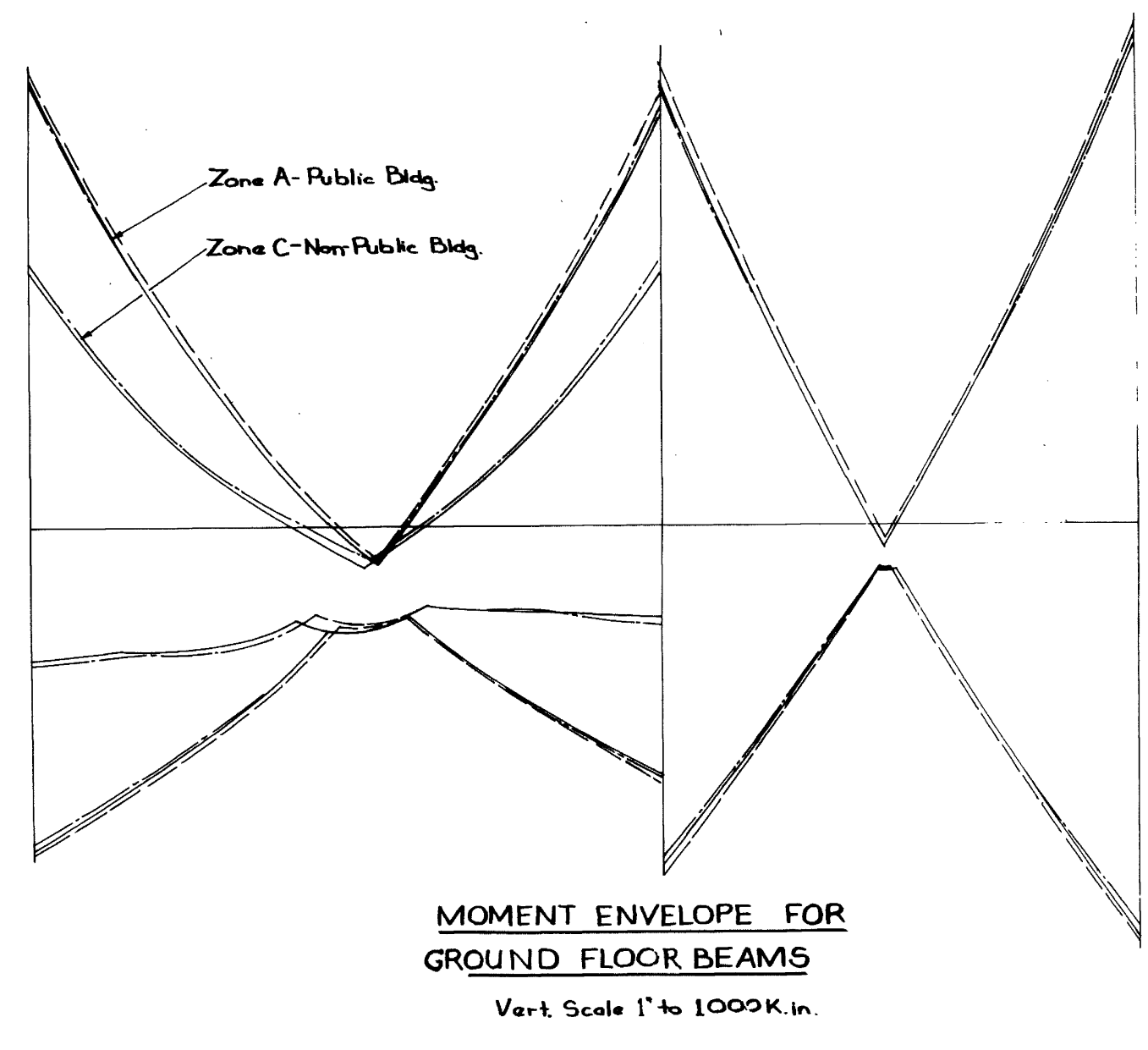
$\left.\begin{array}{l}\text { 1.5DL. } 1.8 L . L . \\ 1.25(D . L+S L L .) \pm 1.25 E(0 .+3 . L)\end{array}\right\}$
$0 \cdot 9(D L+$ S.L.L $) \pm 1 \cdot 25=(0 .+$ S.L. $)\}$ Shown.
$1.40 L,+1.7 L$.
$1.05 \mathrm{DL}+1 \cdot 27 L L A+1.25 E(D+S L)$
$0.90 .2 . \pm 1 \cdot 25 E(0.32)$
$\left.\begin{array}{l}\text { 1.4DL.+1.7LL.R } \\ 1.05 \mathrm{DL}+1.27 L L R \pm 1.4 E .(0) \\ 0.9 \mathrm{DL} \pm 1.4 E(0)\end{array}\right\}$
$0.9 \mathrm{ac} \pm 1.4=(0)$ Shown. 


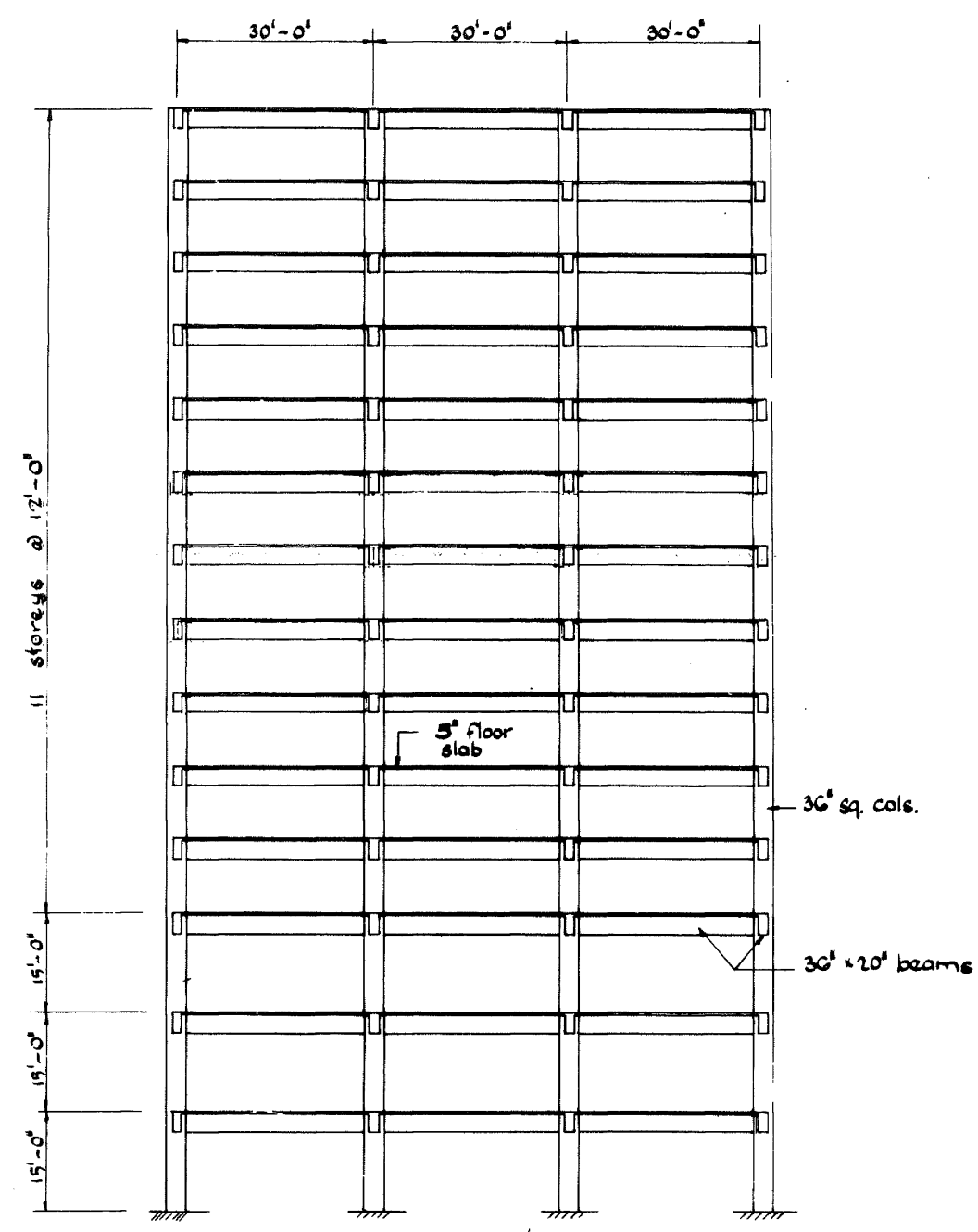

$A-A$

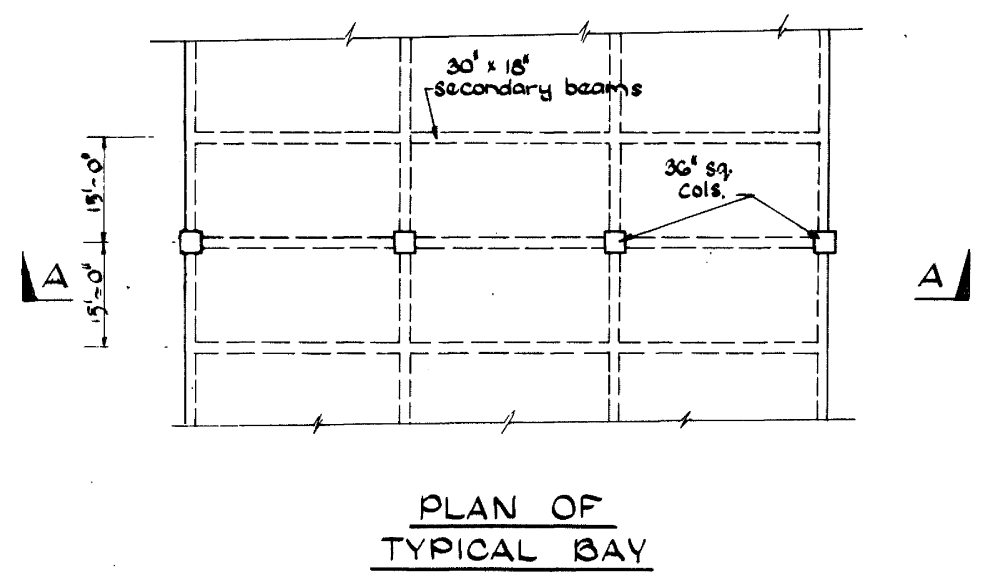




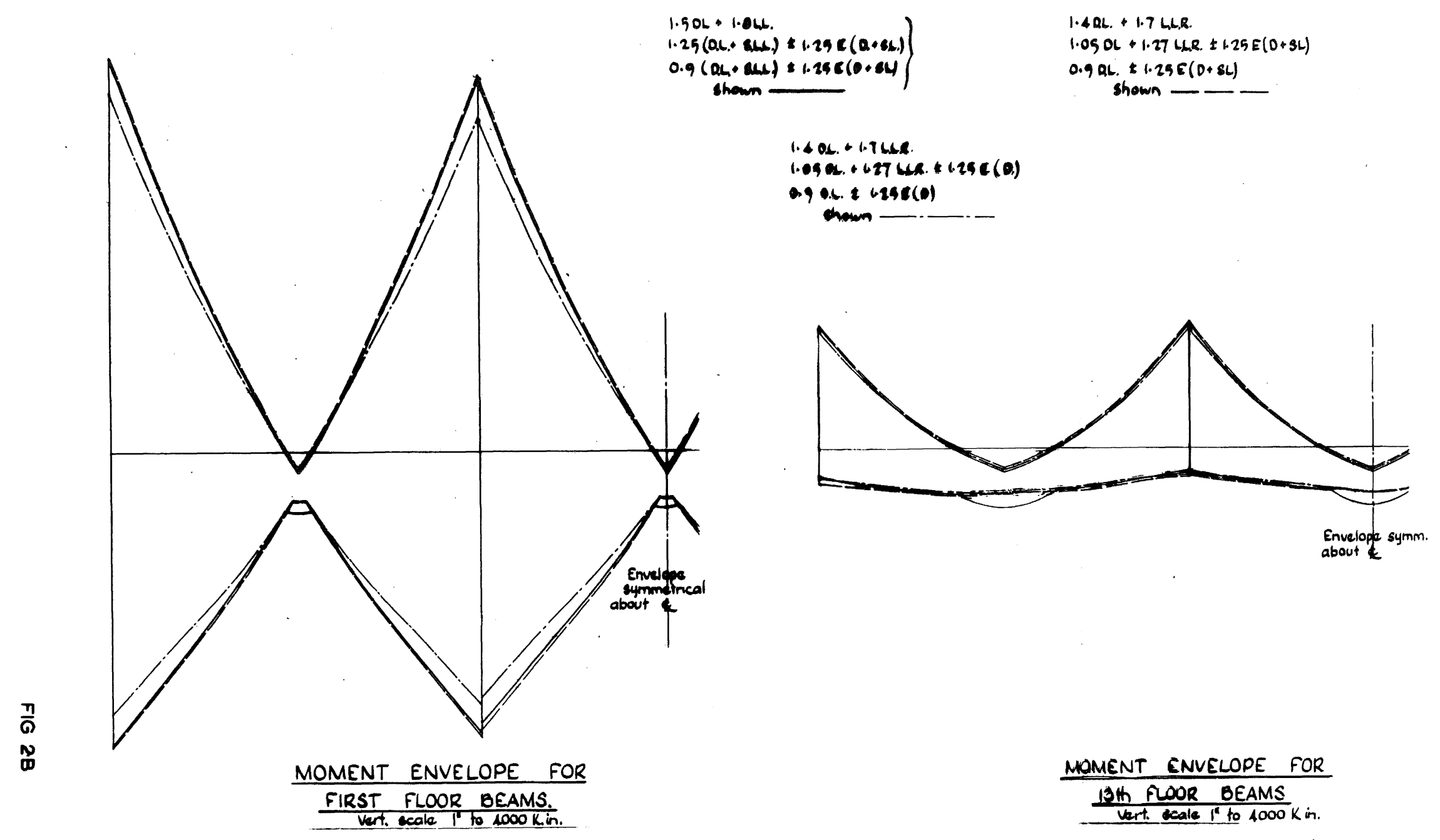




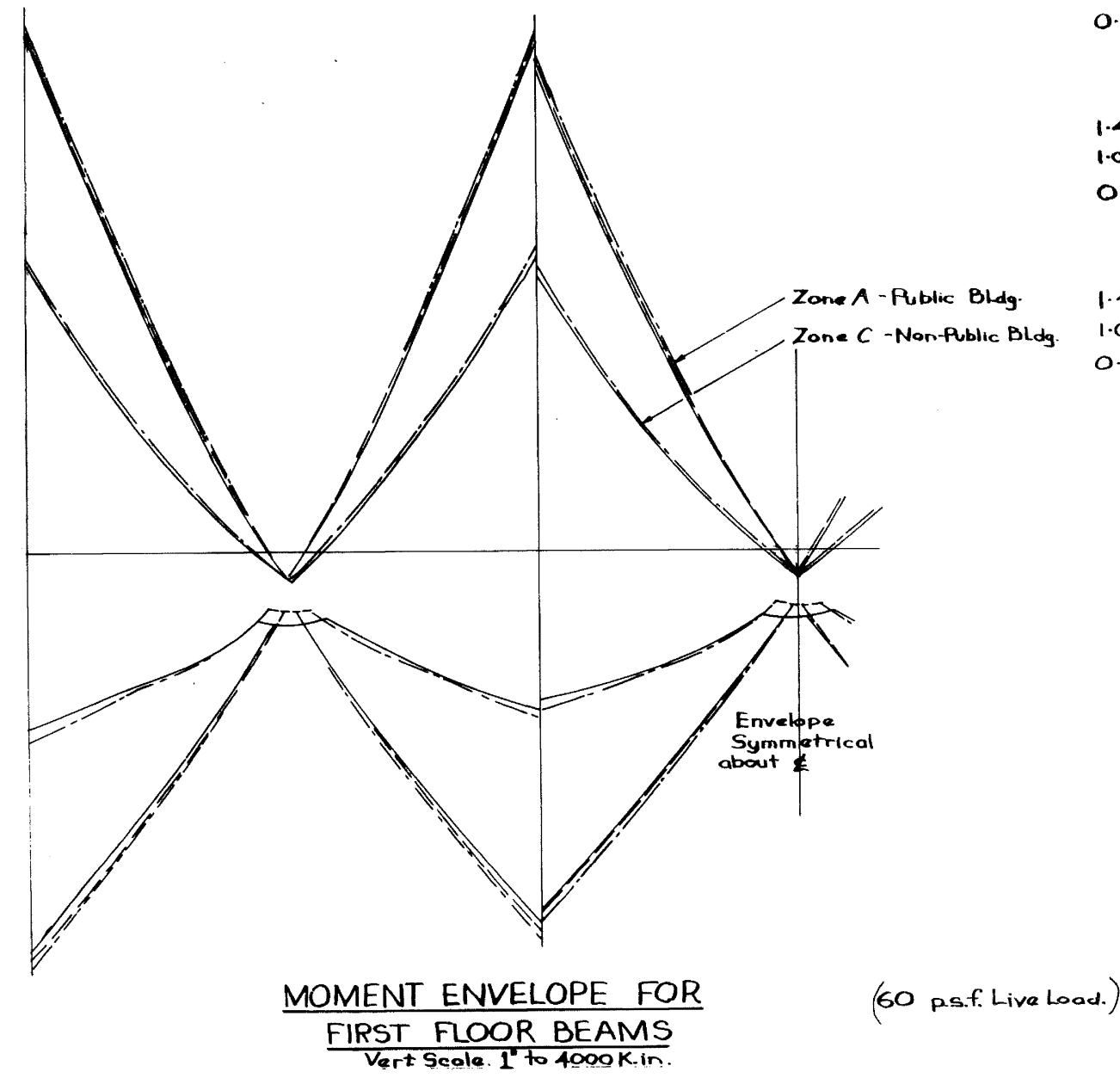

$1.5 \mathrm{DL}+1.8 \mathrm{LL}$

$1.25(02+\sin )+1 \cdot 25 e \cdot(\mathrm{D}+\mathrm{se})\}$

$0.9(0 L .321) \pm 1.25 E(0 .+52)$

Shown.

1.4 DL. + 1.7 LAR.

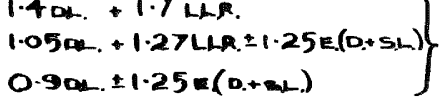

show

$1.40 L+1.7$ LLR.

$1.050 x+1 \cdot 27 L L A \pm 1 \cdot 4 E(0$.

$0.902 . \pm 1.4$ e.(o.)

$$
\text { Shown. }
$$

\section{FIRST FLOOR BEAMS}

